\title{
Prevalence and Factors Associated with Malnutrition Among Children Aged 6-59 Months in Badbaado Camp in Mogadishu Somalia
}

\author{
Ali Sheikh Mohamed Omer ${ }^{1, *}$, Abdirizak Mohamud Yusuf ${ }^{2}$, Adan Yusuf Mahdi ${ }^{3}$, \\ Fardowsa Abdikarim Daud ${ }^{3}$ \\ ${ }^{1}$ Postgraduate Studies Centre, Benadir University, Mogadishu, Somalia \\ ${ }^{2}$ Department of Public Health, Head of WASH Section, Ministry of Health, Mogadishu, Somalia \\ ${ }^{3}$ Nutrition Technical Specialist, Save the Children, Mogadishu, Somalia \\ Email address: \\ alibotany2@gmail.com (A. S. M. Omer), abdirizak992@gmail.com (A. M. Yusuf), adan.mahdi@savethechildren.org (A. Y. Mahdi), \\ firdawsa80@hotmail.com (F. A. Daud) \\ ${ }^{*}$ Corresponding author
}

\section{To cite this article:}

Ali Sheikh Mohamed Omer, Abdirizak Mohamud Yusuf, Adan Yusuf Mahdi, Fardowsa Abdikarim Daud. Prevalence and Factors Associated with Malnutrition Among Children Aged 6-59 Months in Badbaado Camp in Mogadishu Somalia. Central African Journal of Public Health. Vol. 6, No. 3, 2020, pp. 136-143. doi: 10.11648/j.cajph.20200603.15

Received: March 4, 2020; Accepted: March 23, 2020; Published: April 21, 2020

\begin{abstract}
The purpose was to determine the prevalence and factors associated with malnutrition among children age 6-59 months in Badbaado IDP camp in Mogadishu Somalia. Since 1990 in southern central Somalia, approximately 1.3 million people are internally displaced (IDP) due to war and famine, levels of malnutrition in children under five remain appallingly high at over 15\%. Methods: The study was a cross-sectional. Sample size of 406 respondents was calculated using (Kish 1965) formula. Systematic sampling was used to select the households and a child aged 6-59 months. Pre-tested structured questionnaires were used to collect the socio- demographic characteristics of the children and their caretakers, feeding practices and health factors of the children. Anthropometric measurements of 406 children aged 6-59 months were undertaken. The data was captured using Epi Data version 3.0 and analyzed STATA 12. The anthropometric data were analyzed using ENA SMART. Results: The prevalence of stunting and under-weight was $66 \%$ and $59.9 \%$ respectively, the prevalence of wasting was high $41.6 \%$. Children whose caretaker were employed by public were more likely to be stunted and underweight compared with the children whose caretaker were self-employed ( $\mathrm{p}$ value $=0.0407$ and 0.0278 ) respectively. Children who were consumed inadequate food groups were at risk of being stunted adjusted OR 1.93 95\%CI 0.97-3.84 (P-value=0.06). Conclusion and recommendation: There is high prevalence of malnutrition (wasting, stunting and underweight) among children in the internally displaced people's camps in Badbaado Mogadishu Somalia. Children who started complementary feeding after six months, suffered fever, and those who consumed inadequate food groups were more at risk of becoming stunted. The Ministry of Health of Somalia should create awareness sessions using mass media on prevention malnutrition.
\end{abstract}

Keywords: Prevalence, Malnutrition, Badbaado IDP Camp

\section{Introduction}

Malnutrition is the cellular imbalance between the supply of nutrients, energy and the body's demand for them to ensure growth, maintenance and specific functions [1]. It is widely recognized as a major health problem in developing countries [2], and is high in the East, central and western parts of Africa, with an estimated number of 111 million deaths among children under the age of five years [3]. Malnutrition is a major cause of poor health and increased mortality [4]. Poor nutrition contributes about $35 \%$ of the 9.2 million child-deaths each year globally across the world, about 178 million children younger than five years are stunted representing $32 \%$ of all children worldwide, and a further 19 million have Severe Acute Malnutrition (SAM) [5]. 
Protein energy malnutrition is a major cause of morbidity and mortality in children in sub-Saharan Africa, the prevalence of malnutrition is high in Africa with $38.6 \%$ of the children less than five years stunted, $28.4 \%$ underweight, and $7.2 \%$ wasted. In southern central Somalia, even outside times of crisis, levels of malnutrition in children under five remain appallingly high at over $15 \%$ in most areas; in the north of Somalia, in areas enjoying greater peace, stability and development, malnutrition rates have been consistently lower, with medium rates over the past seven years of about $10 \%$ in Somaliland and 14\% reported in Puntland [6].

\section{Materials and Methods}

\subsection{Study Design, Site and Population}

The study was cross-sectional in nature that involved a descriptive quantitative method. Badbaado camp is located in the Xosh area of Dharkenley district in Mogadishu. Capital city of Somalia. The study area has 5 administrative units that make up the camp. According to the Mayor of Benadir, the camp is composed of approximately $85 \%$ women and children. Most are recently arrived drought/famine-affected IDPs hailing from southern Somalia, [7]. The study population included children aged 6-59 months and their caretakers living in Badbaado IDP camp.

\subsection{Sample Size Calculation and Sampling Technique}

Sample size of 406 respondents was used based on (Kish 1965 formula), using $z^{2} \times p \times q / d^{2}$ considering the following assumptions: $95 \%$ confidence level, estimated proportion $(\mathrm{P})$ of GAM was 34.4. All the five sections of Badbaado IDP camp were sampled. Probability proportion to size sampling was used to select the number of households from each section/unit. Thus the section with a bigger number of households had more participants in the study. A systematic random sampling was used to select the households. To determine the random start (starting household) random numbers were used. At Household level one child aged 6-59 months was selected. In case the household had more than one child aged 6-59months, simple random sampling was done to select one who would participate in the study.

\subsection{Data Collection Tools}

Quantitative method of data collection was employed to investigate the factors associated with malnutrition among children aged 6- 59 months in Badbaado IDP camp. Quantitative data was obtained using semi-structured questionnaire to obtain information on dietary feeding practices of the caretakers, health factors and sociodemographics characteristics of the caretaker and the children in the camp.

\subsection{Data Quality Control}

The questionnaires was pre-tested in Uganda on 20 mothers/caretaker in Nakavali refugee camp before adoption for actual data collection in Mogadishu camp with a purpose of checking clarity, suitability of questions. The supervisors and principal investigator did continuous supervision on daily bases.

\subsection{Data Processing and Analyzing}

The questionnaires were pre-coded before being administered and the same codes were used in data entry. Open-ended questions were post coded and the master coding sheets securely stored. Double data entry was done using Epi-data 3.2.1. Anthropometric data were entered for ENA SMART software. The WHO of malnutrition chart were used to interpret anthropometric measurements of the respondents such as the weight for height (wasting), height for age (stunting) and weight for age (underweight). The data was analyzed using STATA 12.0. Univariate analysis was done; findings were presented as proportions, means and frequencies for all variables. Bivariate analyses were done to determine factors that were significantly associated with wasting, stunting and underweight. Chi square test was used to ascertain statistical significance of the variables at $P$ value $\leq 0.05$. All variables with $p$ value less or equal to 0.2 were entered into logistic regression for father analysis to adjust confounds.

\subsection{Ethical Considerations}

Approval to conduct the study sought from the Makerere University School of Public Health, as guided by the Higher Degrees Research and Ethics committee. Only children whose parents consented were included in the study.

\section{Results}

\subsection{Socio-demographic Characteristics of Caretakers}

Results in Table 1 show that more than half $(58.2 \%)$ of care takers were aged in between 18 and 30 years, while a few $(7.8 \%)$ of the caretakers were less than 18 years, the mean age of the caretakers was 30 years. Majority $(90.7 \%)$ of the care takers were female. The majority 324 (81.6\%) of the respondents were married compared to those who were single $6(1.5 \%)$. Majority of the caretakers 340 $(85.6 \%)$ were not educated while very few $3(0.8 \%)$ had at least acquired secondary level education. One third 132 (33.3\%) of the respondents were civil servants and most of them 337 (84.9\%) had lived in the camp for more than three years. Majority were 13-24 months of age $83(30.7 \%)$ and small number were $49-59$ months of age $32(8.1 \%)$, the mean age of the children were 29.09 and the likelihood of the child being female was almost equal ratio of I: 1 being a boy (51.4: 48.6, Males: Females). Majority of caretakers were mothers $319(80.4 \%)$ while 7 (1.8) were antis or ankles. The mean number of people in the households was 6.76 . 
Table 1 Socio-demographic characteristics of the Caretakers and children.

\begin{tabular}{llll}
\hline Care taker characteristic & Frequency (\%) & Duration in camp & $16(4.0)$ \\
\hline Age & & $<1$ year & $44(11.1)$ \\
$<18$ & $31(7.8)$ & $2-3$ years & $337(84.9)$ \\
$18-30$ & $231(58.2)$ & $>3$ years & $132(33.3)$ \\
$31-40$ & $81(20.4)$ & Occupation & $55(13.9)$ \\
$>40$ & $54(13.6)$ & Civil servant & $44(11.1)$ \\
Sex & & Trader & $27(6.8)$ \\
Male & $37(9.3)$ & Other privately employed & $11(2.8)$ \\
Female & $360(90.7)$ & Artisan & $128(32.2)$ \\
Marital status & & Food service & $320(80.6)$ \\
Single & $6(1.5)$ & Other & $5(1.3)$ \\
Married & $324(81.6)$ & Type of chronic illness & $19(4.8)$ \\
Divorced/separated & $37(9.3)$ & No illness & $10(2.5)$ \\
Widowed & $30(7.6)$ & HIV/AIDs & $43(10.8)$ \\
Education level & & Asthma & \\
No education & $340(85.6)$ & Ulcers & $204(51.4)$ \\
Primary & $12(3.0)$ & Others & $193(48.6)$ \\
Intermediate & $42(10.6)$ & Sex of the child & \\
Secondary & $3(0.8)$ & Male & $319(80.4)$ \\
Age of the child & & Female & $24(6.1)$ \\
$6-12$ & $83(20.9)$ & Relationship with child & $54(13.6)$ \\
$13-24$ & $122(30.7)$ & Mother & \\
$25-36$ & $86(21.7)$ & Father & \\
$37-48$ & $74(18.6)$ & Other relatives & \\
$49-59$ & $32(8.1)$ & &
\end{tabular}

\subsection{Prevalence of Malnutrition}

This study targeted children aged 6-59 months. The results in Figure 1 is showed prevalence of malnutrition that the prevalence of stunting was $66 \%$, wasting 41.6 and under weight, $59.9 \%$ were severely. The prevalence of both global wasting and stunting were higher in the age groups 49-59 months compared to the rest of the age groups. The prevalence of sever wasting was found to be $28.1 \%$ among the children.

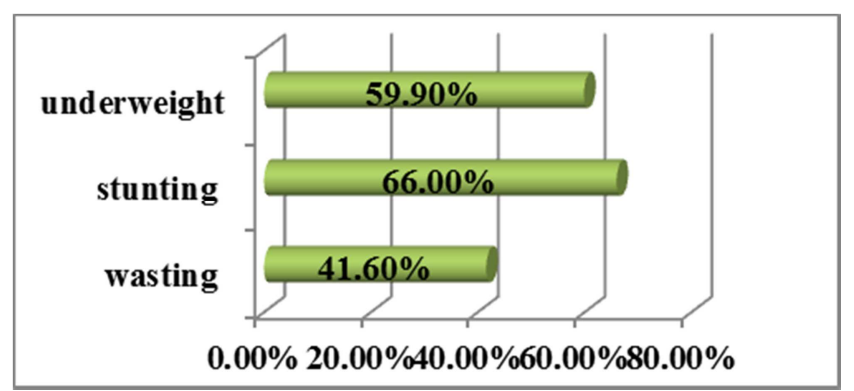

Figure 1. Prevalence of malnutrition.

\subsection{Association Between Socio-demographic Factors with Wasting, Stunting and Underweight}

The only significant factors were sex of the child, age of the child and employment of the care taker. Male children were more likely to be stunted than female children (OR 1.75, $95 \%$ CI $1.14-2.67, \mathrm{p}=0.0 .088$ ).

Employment of the caretaker was found to be associated with both stunting and underweight and was not associated with wasting. Children whose caretakers were employed by public were more likely to be stunted and underweight compared to those whose caretakers were self-employed (OR $1.75,95 \%$ CI $1.75-2.44, \mathrm{p}=0.0407$ and OR $1.61,95 \%$ CI 1.05 $-2.46, \mathrm{p}=0.0278$ ) respectively. Children aged 6-24 months were more likely to be stunted compared with the children aged 25 -59 months (OR 1.55, 95\% CI 1.02 - 2.36, p=0.0398).

Other demographic factors such as; age of caretaker, sex of caretaker, marital status, education level, duration in the camp and relationship with the child, were not significantly associated with malnutrition. Results showing association of social demographics are presented in table 2 below.

Table 2. Socio- demographic factors associated with wasting, stunting and underweight.

\begin{tabular}{|c|c|c|c|c|}
\hline \multirow{2}{*}{ Variables } & \multirow{2}{*}{ Total N } & \multicolumn{3}{|l|}{ Malnutrition } \\
\hline & & Wasting No \% OR (CI) & Stunting No \% OR (CI) & Underweight NO \% OR (CI) \\
\hline \multicolumn{5}{|l|}{ Age of caretaker } \\
\hline$<25$ years & 151 & $60(39.7) 0.89$ & $96(63.6) 0.84$ & $89(58.9) 0.93$ \\
\hline$>25$ years above & 246 & $105(42.7)(0.59-1.34)$ & $166(67.5)(0.5-1.29)$ & $149(60.6)(0.62-1.41)$ \\
\hline \multicolumn{5}{|l|}{ Sex of caretakers } \\
\hline Male & 37 & $17(45.9) 1.22$ & $26(70.3) 1.24$ & $22(59.5) 0.98$ \\
\hline Female & 360 & $148(41.1)(0.62-2.41)$ & $236(65.6)(0.59-2.60)$ & $216(60.0)(0.49-1.95)$ \\
\hline \multicolumn{5}{|l|}{ Sex of the child } \\
\hline Male & 204 & $92(45.1) 1.35$ & $147(72.1) 1.75$ & $131(64.2) 1.44$ \\
\hline Female & 193 & $73(37.8)(0.90-2.02)$ & $115(59.6)(1.14-2.67)^{* *}$ & $107(55.4)(0.96-2.16)$ \\
\hline Marital status & & & & \\
\hline
\end{tabular}




\begin{tabular}{|c|c|c|c|c|}
\hline \multirow{2}{*}{ Variables } & \multirow{2}{*}{ Total N } & \multicolumn{3}{|l|}{ Malnutrition } \\
\hline & & Wasting No \% OR (CI) & Stunting No \% OR (CI) & Underweight NO \% OR (CI) \\
\hline Married & 324 & $135(41.7) 1.02$ & $214(66.0) 1.01$ & $198(61.1) 1.30$ \\
\hline Not married & 73 & $30(41.1)(0.61-1.72)$ & $48(65.8)(0.59-1.73)$ & $40(54.8)(0.78-2.17)$ \\
\hline \multicolumn{5}{|l|}{ Education level } \\
\hline Educated & 57 & $21(36.8) 1.19$ & $39(68.4) 0.88$ & $31(54.4) 1.31$ \\
\hline Non educated & 340 & $144(42.4)(0.4-3.36)$ & $223(65.6)(0.48-1.61)$ & $207(60.9)(0.74-2.30)$ \\
\hline \multicolumn{5}{|l|}{ Duration in camp } \\
\hline$>$ one year & 381 & 159 (41.7) 1.26 & $251(65.9) 0.88$ & $223(58.5) 0.89$ \\
\hline \multicolumn{4}{|l|}{ Employment } & $10(62.5)(0.32-2.51)$ \\
\hline Self employed & 265 & 109 (41.1) 0.95 & $184(69.4) 1.75$ & $169(63.8) 1.61$ \\
\hline \multicolumn{4}{|l|}{ Age of the child } & $69(52.3)(1.05-2.46)^{* *}$ \\
\hline 6-24 months & 205 & $82(40.0) 0.88$ & $145(70.7) 1.54$ & $121(59.0) 0.92$ \\
\hline 25-59 months & 192 & $(8343.2)(0.59-1.31)$ & $117(60.9)(1.02-2.36)^{* *}$ & $117(60.9)(0.62-1.38)$ \\
\hline \multicolumn{5}{|c|}{ Relationship with child } \\
\hline Other caretaker & 78 & $36(46.2) 1.26$ & $51(65.4) 0.97$ & $50(64.1) 1.24$ \\
\hline Biological mother & 319 & $129(40.4)(0.77-2.08)$ & $211(66.1)(0.57-1.63)$ & $188(58.9)(0.74-2.08)$ \\
\hline
\end{tabular}

$* *=$ significant where $\mathrm{P}$-value $<0.05$.

\subsection{Association Between Dietary Practices and Wasting, Stunting and Underweight}

The results in table 3 below show the association between dietary feeding practices, wasting, stunting and underweight. Age of initiation of complementary feeding and dietary diversity scores were found to be associated with stunting. Children who started complementary feeding at six months were less likely to be stunted than those who started after six months (OR 0.59, 95\% CI 0.37-0.93, $\mathrm{P}=0.0219$ ). Children who consumed inadequate food groups were more likely to be stunted than the children who consumed adequate food groups (OR 1.97, 95\% CI 1.02-3.77, $\mathrm{P}=0.044$.

Other feeding practices such as ever breast fed, still breast feeding, initiation of breastfeeding and age of stopping breast feeding were not associated with malnutrition.

Table 3. Dietary practices associated with wasting, stunting and underweight.

\begin{tabular}{|c|c|c|c|c|}
\hline \multirow{2}{*}{ Variables } & \multirow{2}{*}{ Total N } & \multicolumn{3}{|l|}{ Malnutrition } \\
\hline & & Wasting No \% OR (CI) & Stunting No \% OR (CI) & Underweight NO \% OR (CI) \\
\hline \multicolumn{5}{|l|}{ Ever breast feed } \\
\hline Yes & 380 & 155 (40.8) 0.48 & $252(66.3) 1.38$ & $226(59.5) 0.61$ \\
\hline No & 17 & $10(58.8)(0.18-1.30)$ & $10(58.8)(0.51-0.71)$ & $12(70.6)(0.21-1.77)$ \\
\hline \multicolumn{5}{|l|}{ Still breast feeding } \\
\hline Yes & 87 & 34 (39.1) 0.90 & $56(64.4) 1.02$ & $49(56.3) 0.85$ \\
\hline No & 293 & $122(41.6)(0.55-1.47)$ & $194(66.2)(0.61-0.70)$ & $117(60.4)(0.52-1.37)$ \\
\hline Within one hour & 312 & 127 (40.7) 0.85 & $206(66.0) 1.01$ & $186(59.6) 0.94$ \\
\hline After one hour & 85 & $38(44.7)(0.52-1.38)$ & $56(65.9)(0.61-1.67)$ & $52(61.2)(0.57-1.53)$ \\
\hline \multicolumn{5}{|l|}{ Age of stop breast feeding } \\
\hline$<$ or equal 24 months & 287 & $117(40.8) 0.89$ & $106(71.8) 0.98$ & $171(59.6) 0.95$ \\
\hline$>24$ months & 110 & $110(43.6)(0.57-0.39)$ & $56(50.9)(0.61-1.56)$ & $67(60.9)(0.60-1.48)$ \\
\hline \multicolumn{5}{|l|}{$\begin{array}{l}\text { Age of initiation of } \\
\text { complementary food }\end{array}$} \\
\hline \multicolumn{5}{|l|}{ Timely introduction $\mathrm{CF}$} \\
\hline \multicolumn{5}{|l|}{ Dietary DDs } \\
\hline In adequate & 58 & $29(50.0) 1.49$ & 45 (77.6) 1.97 & $33(56.9) 1.44$ \\
\hline Adequate & 339 & $136(40.1)(0.85-2.62)$ & $217(64.0)(1.02-3.77)^{* *}$ & $199(58.7)(0.80-2.61)$ \\
\hline
\end{tabular}

Significant where P-value $<0.05=* *$.

\subsection{Association Between Health Factors and Wasting, Stunting and Underweight}

The results in table 4 below show that diarrhea and immunization were significantly associated with wasting, fever was associated with stunting. Children who reported to have suffered from diarrhea two weeks prior data collection, were1.64 more likely to be wasted than their counter parts
(OR 1.64, 95\% CI 1.07-2.54, $\mathrm{P}=0.0232$ ). Diarrhea was not found to be associated with stunting and underweight in this study. Children who did not experience fever in the last two weeks prior to the data collection were less likely to be stunted than the children who experienced with fever (OR $0.45,95 \% \mathrm{Cl} 0.23-0.87, \mathrm{p}$ value $=0.0141)$. However fever was not associated with wasting and underweight in this study. The study also revealed that children who received 
completely immunization were less likely to be wasted than children who were not immunized or those partially immunized (OR 0.76, 95\% CI 0.45-1.01, P-value $=0.05$ ).
Other health factors such as; cough, measles, treat water, dispose faces and de-worming were not to significantly associated with malnutrition in this study.

Table 4. Health factors associated with wasting, stunting and underweight.

\begin{tabular}{|c|c|c|c|c|}
\hline \multirow{2}{*}{ Variables } & \multirow{2}{*}{ Total N } & \multicolumn{3}{|l|}{ Malnutrition } \\
\hline & & Wasting No \% OR (CI) & Stunting No \% OR (CI) & Underweight NO \% OR (CI) \\
\hline \multicolumn{5}{|l|}{ Diarrhea } \\
\hline Yes & 122 & $61(50.0) 1.64$ & $81(66.4) 1.03$ & $77(63.1) 1.21$ \\
\hline No & 275 & $104(37.8)(1.07-2.54)^{*}$ & $181(65.8)(0.65-1.61)$ & $161(58.5)(0.78-1.88)$ \\
\hline \multicolumn{5}{|l|}{ Cough } \\
\hline Yes & 111 & $43(38.7) 0.85$ & $70(63.1) 0.84$ & $62(55.9) 0.79$ \\
\hline No & 286 & $122(42.7)(0.54-1.33)$ & $192(67.1)(0.53-1.32)$ & $176(61.5)(0.51-1.23)$ \\
\hline Yes & 41 & $15(36.6) 0.79$ & $20(48.8) 0.45$ & $21(51.2) 0.67$ \\
\hline No & 356 & $150(42.1)(0.4-1.55)$ & $242(68.0)(0.23-0.87)^{* *}$ & $217(61.0)(0.35-1.29)$ \\
\hline \multicolumn{5}{|l|}{ Measles } \\
\hline Yes & 227 & 89 (39.2) 0.80 & $142(62.6) 0.88$ & $130(57.3) 0.77$ \\
\hline No & 170 & $76(44.7)(0.53-1.19)$ & $115(67.6)(0.58-1.34)$ & $108(63.5)(0.51-1.16)$ \\
\hline \multicolumn{5}{|l|}{ Treat water } \\
\hline Treated water & 290 & 120 (41.4) 0.97 & $189(65.2) 0.87$ & $170(58.6) 0.81$ \\
\hline Community latrine/bush & 366 & $153(41.8) 1.14$ & 189 (51.6) 0.78 & $220(60.1) 1.09$ \\
\hline $\begin{array}{l}\text { Private latrine } \\
\text { Immunization status }\end{array}$ & 31 & $12(38.7)(0.54-2.41)$ & $73(235.5)(0.35-1.75)$ & $18(58.1)(0.52-2.29)$ \\
\hline Not or partially immunized & 234 & 88 (37.6) 0.67 & $161(68.8) 1.35$ & $138(59.0) 0.91$ \\
\hline $\begin{array}{l}\text { Completely immunized } \\
\text { De-worming last 3months }\end{array}$ & 163 & $77(47.2)(0.45-1.01)^{* *}$ & $101(62.0)(0.89-2.06)$ & $100(61.3)(0.60-1.53)$ \\
\hline Yes & 121 & $51(42.1) 1.04$ & $78(64.5) 0.91$ & $71(58.7) 0.93$ \\
\hline No & 276 & $114(41.3)(0.67-60)$ & $184(66.7)(0.58-1.42)$ & $167(60.5)(0.60-1.43)$ \\
\hline
\end{tabular}

Significant where $\mathrm{P}$-value $<0.05=* *$.

\subsection{Factors Associated with Wasting, Stunting and Underweight on Logistic Regression Analysis}

Table 5 show results of logistical regression analysis. Variables with $p$ value less or equal to 0.2 were selected and those which were reported significant in other studies. The selected variables for wasting included: sex of the child, relationship with child, ever breast fed, time initiation of breast milk, timely introduction of complementary feeding, diarrhea and fever, immunization status and de-worming. For stunting, the variables selected were sex of the child, employment, age of the child, ever breast fed, time of initiation of breast feeding, time of introduction of complementary feeding, dietary diversity scores, fever, diarrhea, cough and de-worming while for underweight; sex of the child, employment, ever breast fed, initiation of breast milk, age of initiation of breast feeding, dietary diversity scores, diarrhea, cough and fever were selected.

On logistic regression, diarrhea (adjusted OR 1.67, 95\% $\mathrm{Cl} .07-2.61, \mathrm{P}=0.024)$ was significant associated with wasting. Children whose caretakers were employed by public were more likely to be stunted and underweight compared to children whose caretakers were self-employed. (Adjusted OR $1.60,95 \mathrm{CI} \% 1.04-2.46, \mathrm{p}=0.033$ ).

Further analysis revealed that children who were not immunized or partially immunized were more likely to be wasted than child who completed immunization (Adjusted OR 1.67, 95\% CI 1.07-2.61, $\mathrm{P}=0.024$ ). Male children were more likely to be stunted than females (Adjusted OR 1.77, 95\%CI 1.14-2.74, $\mathrm{p}=0.011)$. Children who started complementary feeding after six month were more likely to be stunted than children who started before six months (adjusted OR 0.60, 95\%CI 0.37-0.98, p=0.041). Dietary diversity scores were associated with stunting; children who consumed inadequate food groups were more likely to be stunted than those who consumed adequate food groups (Adjusted OR 1.93, 95\%CI 0.97-3.84, P-value=0.06). Children who experienced fever the last two weeks prior the data collection were more likely to be stunted than the child who did not experience with fever (Adjusted OR 0.44, $95 \%$ CI $0.22-0.89, \mathrm{P}=0.22$ ).

Table 5. Factors associated with wasting, stunting and underweight on logistic regression analysis.

\begin{tabular}{|c|c|c|c|}
\hline \multirow{2}{*}{ Variables } & \multicolumn{3}{|l|}{ Malnutrition } \\
\hline & Wasting Adjusted OR (CI) & Stunting Adjusted OR (CI) & Underweight Adjusted OR (CI) \\
\hline $\begin{array}{l}\text { Sex of the child } \\
\text { Male } \\
\text { Female } \\
\text { Employment }\end{array}$ & $1.13(0.89-2.04)^{*}$ & $1.77(1.14-2.74)^{*}$ & $1.44(0.96-2.19)$ \\
\hline
\end{tabular}




\begin{tabular}{|c|c|c|c|}
\hline \multirow{2}{*}{ Variables } & \multicolumn{3}{|l|}{ Malnutrition } \\
\hline & Wasting Adjusted OR (CI) & Stunting Adjusted OR (CI) & Underweight Adjusted OR (CI) \\
\hline Self-employer & & $1.59(1.01-2.51)^{*}$ & $1.60(1.04-2.46)^{*}$ \\
\hline \multicolumn{4}{|l|}{ Public employer } \\
\hline \multicolumn{4}{|l|}{ Age of the child } \\
\hline 6-24 months & & $1.46(0.94-2.28) *$ & \\
\hline \multicolumn{4}{|l|}{$25-59$ months } \\
\hline \multicolumn{4}{|l|}{ Relationship with child } \\
\hline Other caretaker & $1.23(0.73-2.08)$ & & \\
\hline \multicolumn{4}{|l|}{ Biological mother } \\
\hline \multicolumn{4}{|l|}{ Ever breast feed } \\
\hline Yes & $0.40(0.13-1.25)^{*}$ & $0.96(0.30-3.02)$ & \\
\hline No & & & $0.52(1.16-1.69)$ \\
\hline \multicolumn{4}{|l|}{ Time put breast feed } \\
\hline \multicolumn{3}{|c|}{ After one hour } & $1.03(0.60-1.79)$ \\
\hline \multicolumn{4}{|c|}{ Age of initiation complementary feeding } \\
\hline $\begin{array}{l}\text { At } 6 \text { months } \\
>\text { or equal } 6 \text { months }\end{array}$ & $0.73(0.45-1.18)^{*}$ & $0.60(0.37-0.98)^{*}$ & $0.83(0.52-1.32)$ \\
\hline \multicolumn{4}{|l|}{ Dietary DD scores } \\
\hline \multicolumn{4}{|l|}{ Adequate } \\
\hline \multicolumn{4}{|l|}{ Diarrhea } \\
\hline \multicolumn{2}{|l|}{ No } & $0.89(0.55-1.43)$ & $0.65(0.33-1.27)$ \\
\hline \multicolumn{4}{|l|}{ Fever } \\
\hline Yes & $0.83(0.41-1.66)$ & $0.44(0.22-0.89)^{*}$ & $0.72(0.45-1.14)$ \\
\hline \multicolumn{4}{|l|}{ No } \\
\hline \multicolumn{4}{|l|}{ Cough } \\
\hline Yes & & & $1.17(0.74-1.84)$ \\
\hline \multicolumn{4}{|l|}{ No } \\
\hline \multicolumn{4}{|l|}{ Immunization status } \\
\hline Not/partially immunized & $0.61(0.39-0.94)$ & & \\
\hline \multicolumn{4}{|l|}{ Completely immunized } \\
\hline De-worming & & & \\
\hline Yes & $1.51(0.72-1.83)$ & $0.79(0.49-1.28)$ & \\
\hline No & & & \\
\hline
\end{tabular}

Significant where P-value $<0.05=* *$.

\section{Discussion}

The study shows an acceptably high prevalence of stunting and under-weight $66 \%$ and $59.9 \%$ respectively, the prevalence of wasting was also high $41.6 \%$ in Badbaado camp in Mogadishu. Our findings indicate high increment in the prevalence of malnutrition compared to those reported in previous studies [8]. This can explained more than two third $80 \%$ of the children did not exclusively breastfeed. In other hand, the fact that the study was conducted during drought season (Jiilal) production of crops was less which would have resulted into high market prices of food thus not affordable to most people, so that low economic people could not buy everything they need from the market so, that they may end up to be malnutrition due to the price of the market. Stated that the rapid price hike seems to have evened out under nutrition in a way that deepens the Bangladesh malnutrition [10].

Children whose caretakers were employed by public were more likely to be stunted and underweight compared with the children whose caretaker was self-employed. This is because the caretakers who were self-employed was more likely to get daily income and properly feed her child compared to the caretakers who were employed by the public, whose monthly income would probably not be enough. In Somalia civil servants do earn \$25-30 and this money is not enough to feed their families hence their children are more likely to be stunted or underweight. This confirms the findings of the study that the underweight and stunting were common in children whose mothers earn less salary in the month [11].

This study showed that children who were aged 6-24 months had a higher risk of suffering from stunting compared to the older age group (25-59 months). The findings are consistent with research that has been done among internally displaced population in northern Uganda.

In Badbaado setting, several factors including; early stopping of breast feeding, poor weaning practices, education of the mother and diarrhea may contribute to poor nutritional status of the younger children. Furthermore, one third of the caretakers were civil servants, they were away from their homes leaving the young children (less than 2 years) to feed with the older children. This might have been one of the factors which predisposed the younger siblings to under feeding, stated that Women's work is significantly associated with stunting and wasting during infancy, [12].

The study revealed that male children were more likely to be stunted than females. Our findings are consistent with the 
study that was done in the IDP camp in northern Uganda [13]. The explanations could be that boys are rare at home. They tend to be active, running around in the neighborhood as compared to the female children who probably eat whatever small feeds that their mothers get since they are always with them at home. Furthermore, a study reported that boys are more stunted than girls in Sub-Saharan Africa [14].

Children who were started on complementary feeding after six months were more likely to be stunted than those who started at six months. Other feeding practices assessed in this study were not associated with malnutrition. Our findings were consistent with study that was stated starting complementary feeding late at seventh month or beyond could lead to macro and micro nutrient deficiency [15]. This would relate to the education level of the caretaker. Mothers who had educational level of secondary and above were 3.8 times more likely to timely introduce and practice appropriate complementary feeding than those mothers who had no education [16]. Indeed, more than two third (85.6\%) of the caretaker of Badbaado setting were not educated.

Dietary diversity scores were associated with stunting. Children who consumed inadequate food groups were more likely to be stunted than the children who consumed adequate food groups. Our findings are consistent with previous studies. This could be attributed to maternal education in Badbaado setting due to lack of dietary diversity is a particularly severe problem among poor populations in the developing world, because their diets are predominantly based on starchy staples and often include little or no animal products and few fresh fruits and vegetables. These plantbased diets tend to be low in a number of macro and micronutrients [17]. Indeed Badbaado setting depends on humanitarian aids, which provide food with little or no animal products.

Children who suffered from diarrhea in the last two weeks prior to this study were 1.64times more likely to be wasted than the children who did not suffer from diarrhea. Diarrhea was not associated with stunting and underweight in this research; our results are consistent with other studies [18]. This could be due to introduction of water or fluids at birth and before six months which may have increased exposure to contamination resulting in infant diarrhea. The introduction of water or other fluids alone was enough to increase the risk of diarrhea in breast-fed infants [19]. In addition, reported that exposure to diarrhea causing agents is frequently related to use of contaminated water and unhygienic practices in food preparation and disposal of excreta. This could be common in Badbaado setting.

The study revealed that children who experienced malaria two weeks before the study were more likely to be stunted than the children who did not experience malaria. Malaria was not associated with wasting and underweight in this research. Our study is consistent with previous studies. The reason could be that malaria affected their appetite hence food intake resulting in to poor nutritional status in these children [20].

This study also revealed that children who were not immunized or partially immunized were more likely to be wasted than the children who completed immunization. This conforms to who stated that immunization status is significantly associated with the presence of under nutrition [21].

\section{Limitations of the Research}

The DD scores were constructed based on a simple count of the number of food groups consumed. No information on portion sizes and amount of intake was collected. The study lies in the uncertainty inherent in the fortnightly parental recall method for the diseases that the child experienced i.e. malaria, cough, and diarrhea. As well as to collect information about feeding practices were based on recall which create recall bias.

\section{Conclusion and Recommendation}

The study shows unacceptably high prevalence of stunting and under-weight $66 \%$ and $59.9 \%$ respectively, the prevalence of wasting was high (41.6\%) in Badbaado camp in Mogadishu. Children whose caretakers were employed by public were more likely to be stunted and underweight compared to those whose caretakers were self-employed. Additionally, children who started complementary feeding after six month and those who consumed food groups inadequately were at risk of being stunted. Likewise, children who experienced fever the last two weeks prior to the date collection were more likely to be stunted than the child who did not experience with fever.

Somalia needs to set up policies on nutrition such as the food and nutrition policy and emphasis should be to put on people in camps due to the large population of children who are in camps in order to reduce the high levels of malnutrition. The stakeholders (local government and relief organizations) involved, encourage backyard farming to improve utilization of fruits and vegetables and emphasize and promoted key messages regarding infant- feeding should and its role to the child's growth. The Ministry of Health of Somalia should create awareness sessions using mass media on prevention malnutrition and water treatment and management, also promote routine immunization program.

\section{References}

[1] Olwedo, M. A., E. Mworozi, et al. (2009). "Factors associated with malnutrition among children in internally displaced person's camps, northern Uganda." African health sciences 8 (4): 244-252.

[2] Joseph, Rebello et al. 2011. "Prevalence of malnutrition in rural Karnataka, South India: a comparison of anthropometric indicators." Journal of Health, Population and Nutrition (JHPN) 20 (3): 239-244.

[3] Yasir Khan, M., Zulfiqar A. Bhutta, MBBS, FRCP, FRCPCH, FCPS, PhD* (2012). "Nutritional Deficiencies in the Developing World: Current Status and Opportunities for Intervention." Pediatr Clin N Am 57: 1409-1441. 
[4] Grantham-McGregor, S., Y. B. Cheung, et al. (2007). "Developmental potential in the first 5 years for children in developing countries." The Lancet 369 (9555): 60-70.

[5] Khan, Y. and Z. A. Bhutta (2010). "Nutritional deficiencies in the developing world: current status and opportunities for intervention." Pediatric Clinics of North America 57 (6): $1409-1441$

[6] Kassim, I., A. Seal, et al. (2010). "National micronutrient and anthropometric survey, Somalia 2009."

[7] UNOCHA (27-28 July 2011). Somalia protection cluster badbado IDP camp rapid protection assessment.

[8] CUNLIFFE, J., K. GHARBI, et al. (2000). Anthropometrical Survey IDP Camps in Mogadishu Somalia. Mogadishu.

[9] Das, M. S. M. P. N. C. (2009). Impact of the Food Price Hike on Nutritional Status of Women and Children 38. Dhaka, Research and Evaluation Division.

[10] Senbanjo IO (FWACP), A. O. F., ***Adejuyigbe EA (FMCPaed) (2004). Influence of socio-economic factors on nutritional status.

[11] Ukwuani, F. A. and C. M. Suchindran (2003). "Implications of women's work for child nutritional status in sub-Saharan Africa: a case study of Nigeria." Social Science \& Medicine 56 (10): 2109-2121.

[12] Wamani, H., A. N. Åstrøm, et al. (2007). "Boys are more stunted than girls in sub-Saharan Africa: a meta-analysis of 16 demographic and health surveys." BMC pediatrics 7 (1): 17.

[13] Shumey, A., M. Demissie, et al. (2013). "Timely initiation of complementary feeding and associated factors among children aged 6 to 12 months in Northern Ethiopia: an institution-based cross-sectional study." BMC public health 13 (1): 1050.
[14] Mekbib, E., A. Shumey, et al. (2014). "Magnitude and factors associated with appropriate complementary feeding among mothers having children 6-23 months-of-age in Northern Ethiopia; a community-based cross-sectional study." Journal of Food and Nutrition Sciences 2 (2): 36-42.

[15] Ruel, M. T. (2003). "Is dietary diversity an indicator of food security or dietary quality? A review of measurement issues and research needs." Food Nutrition Bull 24 (2): 231-232.

[16] Weisz, A., G. Meuli, et al. (2011). "The duration of diarrhea and fever is associated with growth faltering in rural Malawian children aged 6-18 months." Nutrition J 10: 25.

[17] Lartey, A., A. Manu, et al. (2000). "Predictors of growth from 1 to 18 months among breast-fed Ghanaian infants." European journal of clinical nutrition 54 (1): 41-49.

[18] KAGENI, K. L. (2011). Diarrhea morbidity and nutritional status among pre- school children of hawking mothers in Nairobi city markets. public health. NAIROBI Kenyatta University. Master's degree.

[19] Friedman, J. F., A. M. Kwena, et al. (2005). "Malaria and nutritional status among pre-school children: results from cross-sectional surveys in western Kenya." The American journal of tropical medicine and hygiene 73 (4): 698-704.

[20] Anekwe, T. D. and S. Kumar (2012). "The effect of a vaccination program on child anthropometry: evidence from India's Universal Immunization Program." Journal of Public Health: fds032.

[21] Tamoghna Biswas (MBBS 7th Semester Student) (1), D. P. K. M. M., Dr. Samarendra Biswas (MD) (3) (2011). "Assessment of Health, Nutrition and Immunisation status amongst under 5 children in migratory brick klin population of periurban Kolkata, India." sudanase journal of public health 6 (1). 